\title{
Assessment of results of the mammography screenıngs among women older than 40 years in a residential area
}

\section{Introduction}

Being the most frequent malignant tumor among women in the world; breast cancer constitutes approximately $30 \%$ of women's cancers. ${ }^{1,2}$ The average incidence of breast cancer is $38-40$ in one hundred thousand in the world, 66-67 in one hundred thousand in Europe, and about 40 in one hundred thousand in Turkey. ${ }^{3,4}$ The fact that breast cancer is encountered frequently, could be diagnosed and treated in early stages in today's conditions increases the importance required to be attached to this issue. ${ }^{5}$ Early diagnosis and treatment have a vital importance in preventing and decreasing the deaths induced by breast cancer. Thus, the most common approach that is known and applied in the world is screening programs. These programs aim to raise awareness in individuals regarding cancer, make them understand the importance of early diagnosis, and administer convenient treatment. ${ }^{6,7}$ The early diagnosis suggestions of the American Cancer Society for breast cancer include breast self examination (BSE) every month as from the age of 20 years, clinical breast examination (CBE) in at least every 3 years between the ages of 20-39 years, and both CBE and mammography every year as from the age of 40 years. ${ }^{3}$ According to the national breast cancer screening standards in Turkey; women are recommended to have breast self examination every month as from the age of 20 years, CBE in every 2 years between the ages of 20-40 years and every year between the ages of 40-69 years, and mammography in every two years between the ages of 40-69 years. ${ }^{4}$ On the other hand, women have a lower rate of displaying early diagnosis behaviors of breast cancer. The studies conducted in Turkey have reported that women have insufficient early diagnosis behaviors of breast cancer. As a result of a study, it was determined that while women aged 20 and older regularly had regularly BSE at the rate of $23.4 \%$, women aged 40 and older had mammography at the rate of $3.2 \%{ }^{8}$

Reasons behind why women do not have early diagnosis behaviors of breast cancer involve some factors such as negligence towards screenings, forgetfulness, lack of knowledge, low educational level, time limitation, insufficient income status, inaccessibility to healthcare services, lack of health insurance, failure of getting an appointment, shame for examination/denominational beliefs, no support from family, no advice from the medical personnel, and belief of fatalism. ${ }^{9}$ On the other hand, factors like fear regarding screening methods, diagnosis of breast cancer, and losing breasts are important in terms of determining the early diagnosis behaviors of women. ${ }^{10,11}$

Breast cancer continues to threaten life despite the advancements in health sciences, development of early diagnosis methods, and the increasing sensitivity of society on this issue ${ }^{3}$. Thus, every community is required to reveal the risks of breast cancer, determine the risk groups, and extend its screening programs. ${ }^{12,13}$ Breast cancer could be treated and it has a very high rate of survival when it is diagnosed in early period, which makes the role of healthcare professionals and especially the nurses more important. ${ }^{14}$ Important responsibilities of nurses involve participating in breast cancer

\author{
Volume 3 Issue 3 - 2018
}

\author{
Sevil Biçer,' Gökçe Demir, ${ }^{2}$ Ayla Ünsal, ${ }^{2}$ \\ Yasemin Șadiye Ceyhan ${ }^{2}$ \\ 'Department of Nursing, Faculty of Health Sciences, Erciyes \\ University, Kayseri, Turkey \\ ${ }^{2}$ Department of Nursing, School of Health, Ahi Evran University, \\ Kırșehir, Turkey
}

\section{Correspondence: Sevil Biçer, Department of Nursing, Faculty of Health Sciences, Erciyes University, Kayseri, Turkey, Fax+90352437928I,Tel +90035220766 66/28574,}

Email sevilnurse@mynet.com

Received: March 12, 2018 | Published: May 22, 2018

screening programs, enabling women to regularly display screening behaviors (mammography, CBE and BSE), developing and extending early diagnosis studies, and having an active role in participation in programs. ${ }^{14-16}$

It is also important for nurses to motivate and support women for increasing early diagnosis behaviors. ${ }^{17,18}$ This cross-sectional study was conducted for the purpose of determining the breast cancer risk levels of women older than 40 in a residential area, gaining the habit of having mammography, which is among the early screening programs, directing them for mammography, and assessing the results of mammography.

\section{Materials and methods}

\section{Study population}

The study was conducted in the province of Kırşehir between 1 February and 1 June 2014 in cooperation with the General Secretariat of Public Hospitals Association, Public Health Branch Office. The population of the study consisted of female patients older than 40 , who were hospitalized in the services of Ahi Evran University Research and Training Hospital between these dates, and their relatives. In this cross-sectional study, it was aimed to reach the entire population; however, size of the sample was not determined. Meanwhile, 409 women who agreed to participate in the study were reached. Before the study, an ethics committee and an institutional permission as well as forms of informed consents from the participants were received.

\section{Study design}

In the study, the data were collected by using data collection form, which was prepared by the researcher upon review of the relevant literatüre ${ }^{1,7,16,19,20}$ and breast cancer risk assessment form. The data collection form consists of 23 questions (10 questions regarding the socio-demographic characteristics of participants, 4 questions regarding their reproductive health and obstetrical histories, 
and 9 questions determining their breast cancer knowledge levels and screening behaviors). The Breast Cancer Risk Assessment Form, which was developed by the American Cancer Society for determining the breast cancer risk in women and suggested by the Republic of Turkey Ministry of Health for evaluating the risks of breast cancer, was used. The form consists of 6 parts and 21 items involving the characteristics like age, family history of breast cancer, personal history of breast cancer, child-bearing-age, menstrual history and body structure (calculating the body mass index; $<18.5 \mathrm{~kg} / \mathrm{m} 2$ is classified as slim, $18.5-24.9 \mathrm{~kg} / \mathrm{m} 2$ as normal, $>24.9 \mathrm{~kg} / \mathrm{m}^{2}$ as fat). Based on total score, risk levels are determined as low (200 points and below), moderate (201-300 points), high (301-400 points) and the highest (above 400 points) by scoring appropriately the answers given to risk factors in this form.

The data were collected by the researcher in the hospital environment by using the face-to-face interview technique. The data collection lasted for approximately 20 minutes for each woman. Appointments were received for women, who completed the data collection form and breast cancer risk assessment form, from Kirşehir Early Diagnosis, Screening, and Training Center (KEDSTC) and they were accompanied for having mammography on certain days and hours. Mammography results were evaluated with the doctor of KEDSTC for each woman and women for whom pathology was determined were referred to general surgical outpatient clinics of hospitals in Kayseri or Ankara based on their preference.

\section{Statistical analysis}

The data were analyzed by using the SPSS 16.0 (Statistical Package of Social Sciences) packaged software. As the descriptive statistics; number and percentage (\%) were used for variables determined via counting, and mean \pm standard deviation $(\mathrm{x} \pm \mathrm{sd})$ was used for variables determined via measurement. The convenience of variables, which were determined or calculated through measurement, for normal distribution was numerically examined by using the single-sample Kolmogorov-Smirnov test. While the Mann-Whitney U test was used for determining the difference between the two groups, the Kruskal Wallis test was used for comparing three and more groups. The statistical significance was accepted as $\mathrm{p}<0.05$.

\section{Results}

The women who participated in the study had an age average of $50.0 \pm 7.32$ and were mostly in the age group of $40-49$ years $(48.6 \%)$. It was determined that $68.0 \%$ of the women were primary school graduates, $91.2 \%$ were married, $73.1 \%$ had a nuclear family, $91.4 \%$ had social security, $90.0 \%$ were housewives, $69.7 \%$ had a middle income, and $85.1 \%$ resided in urban areas (Table 1).

Table I Distribution of the women according to some socio-demographic characteristic

\begin{tabular}{|c|c|c|}
\hline Socio-demographic characteristics & Number (n) & Percentage (\%) \\
\hline Age $(\bar{x} \pm \mathrm{ss}=50.0 \pm 7.32)$ & 199 & 48.6 \\
\hline $50-59$ ages & 160 & 39.1 \\
\hline 60 ages and via & 50 & 12.3 \\
\hline \multicolumn{3}{|l|}{ Educational status } \\
\hline Illiterate & 34 & 8.3 \\
\hline Literate & 42 & 10.3 \\
\hline Primary education & 278 & 68 \\
\hline High school & 43 & 10.5 \\
\hline University & 12 & 2.9 \\
\hline \multicolumn{3}{|l|}{ Marital status } \\
\hline Single & 36 & 8.8 \\
\hline Married & 373 & 91.2 \\
\hline \multicolumn{3}{|l|}{ Family type } \\
\hline Nuclear family & 299 & 73.1 \\
\hline Extended family & 99 & 24.2 \\
\hline Broken families & 11 & 2.7 \\
\hline \multicolumn{3}{|l|}{ Social security } \\
\hline Available & 374 & 91.4 \\
\hline Not present & 35 & 8.6 \\
\hline \multicolumn{3}{|l|}{ Profession } \\
\hline Officer & 13 & 3.2 \\
\hline Housewife & 368 & 90 \\
\hline Teacher & 25 & 6.1 \\
\hline Retired & 3 & 0.7 \\
\hline \multicolumn{3}{|l|}{ Income status } \\
\hline Very good & 5 & 1.2 \\
\hline Good & 105 & 25.7 \\
\hline Middle & 285 & 69.7 \\
\hline Bad & 12 & 2.9 \\
\hline Very bad & 2 & 0.5 \\
\hline \multicolumn{3}{|l|}{ Living place } \\
\hline City / urban areas & 348 & 85.1 \\
\hline Village / countryside & 61 & 14.9 \\
\hline Total & 409 & 100 \\
\hline
\end{tabular}


While $80.7 \%$ of the women stated that breast cancer could be diagnosed in early period, $37.4 \%$ stated that the most efficient method in early diagnosis was mammography. It was determined that $46.9 \%$ of the women did not regularly have BSE, $37.9 \%$ had mammography before; $50.9 \%$ of those who had mammography had it 6 months before, $37.3 \%$ had it at the medical advice, and $32.4 \%$ of those who did not have mammography were afraid of the diagnosis of cancer (Table 2).

$57.5 \%$ of the women went through the menopause. $83.2 \%$ of them had no family history of breast cancer, and $98.2 \%$ had no personal history of breast cancer. It was determined that $83.6 \%$ of the women had their first delivery before the age of 30 years, and $59.6 \%$ had an age of menarche as $12-14$ years. Regarding the body structure; $69.2 \%$ had a normal weight. $90.4 \%$ of the women were observed to have a lower risk level according to the breast cancer risk assessment form. As a result of the mammography screenings of women; while normal breast tissues were determined in $42.5 \%$ and nodular lumps were determined in $21.8 \%$ (Table 3 ).

Breast cancer risk score was significantly higher in women who had personal history of breast cancer and a history of breast cancer in their mothers, had no children, menstruated before the age of 11, had a fat body structure, were in the high risk group according to the breast cancer risk assessment form, and had nodular and axillary lymph nodes according to mammography $(\mathrm{p}<0.05)$ (Table 4).

Table 2 Distribution of the women according to their knowledge levels regarding breast cancer early diagnosis methods

\begin{tabular}{lll}
\hline Breast cancer is early detection status & Number (n) & Percentage (\%) \\
\hline Knows & 330 & 80.7 \\
Unknowing & 2 & 0.6 \\
Unideaed & 77 & 18.7 \\
Methods that can be used in early diagnosis & & \\
Breast self-examination & 115 & 28.2 \\
Breast examination performed by doctor / nurse & & \\
Breast ultrasound & 47 & 11.4 \\
Mammography & 73 & 17.8 \\
Biopsy & 153 & 37.4 \\
& 21 & 5.2 \\
Total & 409 & 100 \\
\hline
\end{tabular}

Table 3 Distribution of the women's behaviours regarding breast cancer early diagnosis methods

\begin{tabular}{lll}
\hline Behaviors & Number (n) & Percentage (\%) \\
\hline State of having BSE & 75 & 18.4 \\
Having regularly & 192 & 46.9 \\
Not having regularly & 142 & 34.7 \\
Having occasionally & & \\
State of having had mammography before & 153 & 37.9 \\
Have had & 256 & 62.1 \\
Have not had & & \\
Last date of having mammography (n=153) & 78 & 50.9 \\
6 months ago & 18 & 11.8 \\
6 months -1 year ago & 57 & 37.3 \\
More than 1 year ago & & \\
Reason of having had mammography before (n=153) & 52 & 33.9 \\
Having a palpable stiffness/lump on the breast & 57 & 37.3 \\
At the medical advice & 30 & 19.7 \\
For a control examination & 14 & 9.1 \\
Other & & \\
Reason of not having had mammography before (n=256) & 42 & 16.4 \\
Having no knowledge about mammography & 83 & 32.4 \\
Being afraid of the diagnosis of cancer & 95 & 37.1 \\
Having noone to give information/guide on this issue Other & 36 & 14.1 \\
Total & 409 & 100 \\
\hline
\end{tabular}


Table 4 Distribution of the women according to breast cancer risk factors and risk scores

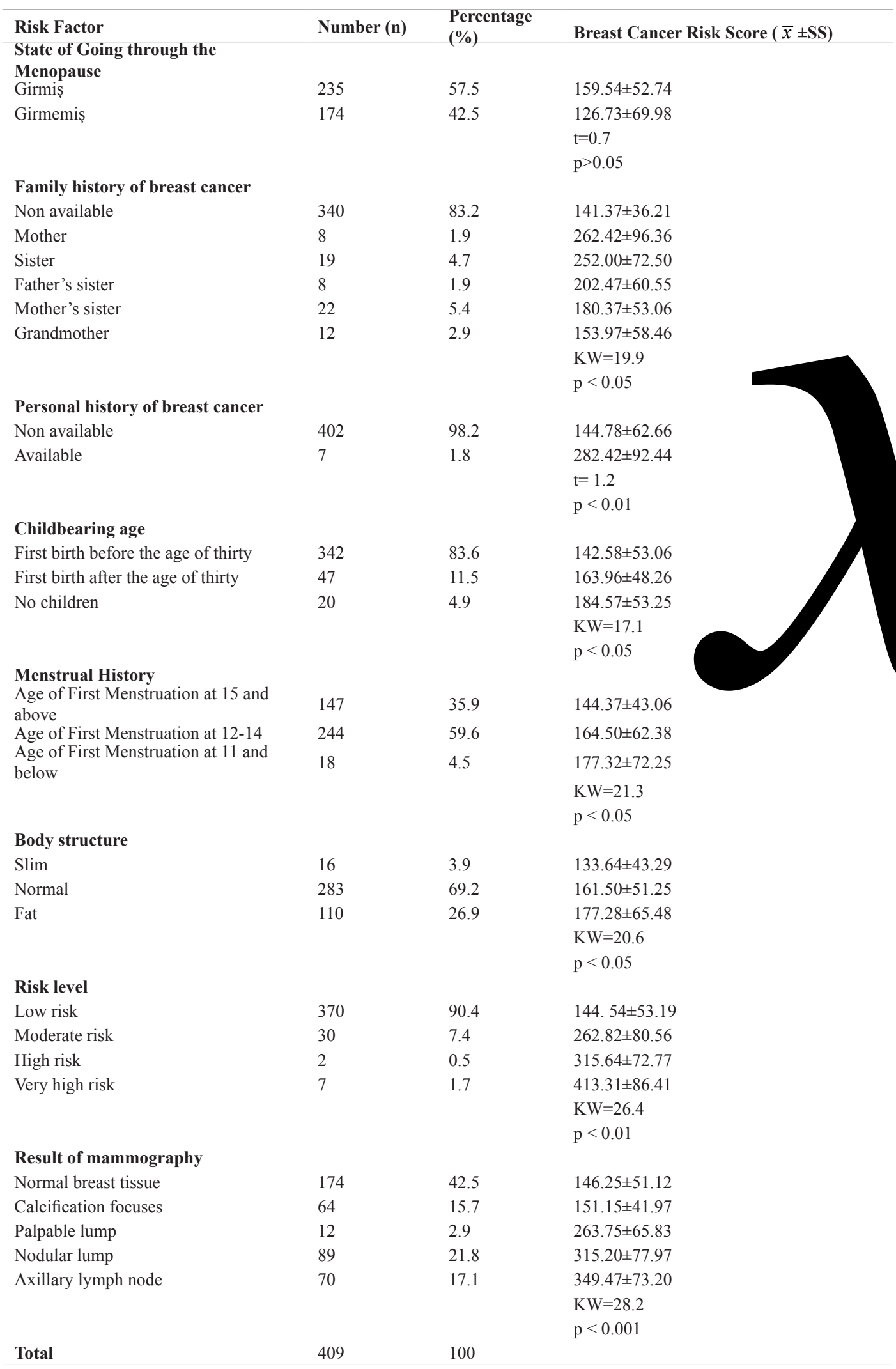


According to the results of mammography; while $61.1 \%$ of the women were required to go for a control examination one year later at the medical advice, $38.9 \%$ were referred toward general surgical outpatient clinics of hospitals in Kayseri or Ankara based on their preference for a more advanced diagnosis.

\section{Discussion}

In this study, it was determined that the women had insufficient behaviors regarding the early diagnosis methods of breast cancer. Reasons behind why the women did not display early diagnosis behavior were thought to be associated with their socio-demographic characteristics, knowledge, values and beliefs, as well as the fear of breast cancer.

In a study conducted by Talbert, ${ }^{21}$ it was determined that even though $98.3 \%$ of the women knew that both mammography and BSE would decrease the breast cancer mortality, only $44.2 \%$ had mammography. In another study, it was observed that $97 \%$ of women had no knowledge about mammography and $86 \%$ did not have mammography. ${ }^{22}$ In parallel with literature; our study determined that even though majority of the women $(80.7 \%)$ had knowledge about the early diagnosis of breast cancer, only a few of them (18.4\%) regularly had BSE, and $62.1 \%$ had not had mammography before. A great majority of them stated the reason for not having mammography as having no knowledge about mammography and being afraid of the diagnosis of cancer. The fact that the individuals had no knowledge about mammography was thought to be associated with lack of communication with the healthcare personnel.

The major roles of the nurses include informing the society, accordingly developing terminal behaviors and changing the acquired undesired behaviors for the protection and maintenance of health. ${ }^{16}$ The functions of nurses regarding the primary protection in early diagnosis include; determining the risky individuals, informing individuals/families and community and raising their awareness by planning trainings. ${ }^{23}$ The interventions that are planned for the primary protection in the early diagnosis of breast cancer are important in reducing the incidence, morbidity, and mortality of breast cancer. ${ }^{24}$ Health education is among the most important functions of nurses in the primary protection. It is required to train women about the normal anatomy and abnormalities of breast, risk factors of breast cancer, and benefits, limitations, and risks of screening methods.

In our study, it was determined that the women who were afraid of breast cancer did not display early diagnosis behaviors to cope with the fear. Being a barrier for women to display early diagnosis behaviors of breast cancer; fear emerges with the thoughts of encountering with a positive result, losing the breast, facing serious problems due to the diagnosis of cancer, losing control over life, as well as the thoughts about death, pain and ache. ${ }^{10,25}$ In the study conducted by Miller et al. ${ }^{26}$ on 84 women, they determined a significant correlation between fear of breast cancer and behaviors of having mammography. Aro et al. ${ }^{27}$ determined that fear, which is one of barriers for women to participate in mammography screenings, negatively affected the early diagnosis behavior at the rate of $21 \%$. Donnelly et al. ${ }^{27}$ found that high level of fear regarding the breast cancer negatively affected having mammography.

In our study, breast cancer risk score was found to be significantly higher in women who had personal history of breast cancer and a history of breast cancer in their mothers, had no children, menstruated before the age of 11 , had a fat body structure, were in the high risk group according to the breast cancer risk assessment form, and had nodular and axillary lymph nodes according to results of mammography. Determining the risk of breast cancer signifies selecting healthy women who have a high risk of getting this disease in the future. Personal breast cancer risk should be determined by examining the risk factors like the history of BRCA $1 / 2$ that is known as breast cancer susceptibility gene, presence of a first degree relative with breast cancer or ovarian cancer, previous radiotherapy on the thorax area, history of lobular carcinoma and f[]amily history, as well as the presence of atypical hyperplasia, which signifies a high risk. ${ }^{28,29}$

A previous study revealed that the Gail model was a reliable model for calculating the personal risk in terms of the development of breast cancer and determined the risk factors in our society. The significant risk factors for the development of breast cancer were respectively determined as follows; history of breast cancer in first degree relatives, history of breast cancer in second degree relatives, having given no birth, not breastfeeding and age. On the other hand, no significant correlation was determined between the age of menarche, menopausal age, and the cancer risk. However, evaluating only those who had given birth; it was concluded that age and number of first birth and duration of breastfeeding were not the factors increasing the breast cancer risk just like age of menarche and the menopausal age and as a result of this study, it was determined that primary factors determining the breast cancer development risk in the Turkish society were either familial or genetic factors and the breast cancer development risk significantly increased with increasing age; however, hormonal factors did not cause a significant increase of risk in our society, in opposition to literatüre. ${ }^{30}$

Even though breast cancer risk assessment gives information about the risk level; it does not give precise information about risk of breast cancer. While mentioning risk of breast cancer, it is required to consider the risk of breast cancer, which would emerge at a certain time, and have screenings according to age, which is the most important independent risk factor, since no risk factor is determined in majority of women with breast cancer. ${ }^{19}$ It is indicated that the deaths caused by breast cancer, which kept increasing until 2000, have decreased in countries where the screenings are applied commonly and while the contribution of screenings is $2 / 3$ in this decrease, the effect of developments in therapeutic methods is $1 / 3 .{ }^{29}$ While early diagnosis is important in the treatment of breast cancer; numerous studies have showed that screening programs also have a positive contribution to the morbidity and mortality of breast cancer. Thus, asymptomatic women should be screened in terms of breast cancer no matter what risk level they have.

\section{Conclusion}

As a result of this study, it was determined that there was a low risk of breast cancer in $90.4 \%$ of in women included in the study and nodular lumps in $21.8 \%$ based on results of the mammography. $38.9 \%$ of the women $(n=89)$ who were observed to have lumps were referred toward general surgical outpatient clinics of hospitals in Kayseri or Ankara based on their preference for a further diagnosis. As the women had insufficient knowledge and behaviors regarding early diagnosis in this study; nurses are required to know their female patients in terms of the risk factors of breast cancer, determine their 
risk levels, encourage and follow them to participate in screening programs in accordance with their age groups, and organize group trainings in cooperation with local governments.

\section{Acknowledgements}

We would like to thank the participants.

\section{Conflict of intrest}

The authors declare no conflicts of interest.

\section{References}

1. Aslan FE, Gürkan A. The risk of breast cancer at the women. The Journal of Breast Health. 2007;3(2):63-8.

2. Suh M, Choi KS, Park B, et al. Trends in cancer screening rates among korean men and women: Results of the Korean National Cancer Screening survey, 2004-2013. Cancer Res Treat. 2016;48(1):1-10.

3. Lee-Lin F, Nguyen T, Pedhiwala N, et al. Mammography screening of Chinese immigrant women: Ever screened versus never screened. Clinical Journal of Oncology Nursing. 2015;42(5):470-8.

4. Republic of Turkey ministry of health health statistics yearbook; 2013.

5. Republic of Turkey public health agency of turkey ministry of health, department of cancer; 2013.

6. Aydıntuğ S. Early diagnosis of breast cancer. Sted. 2004;13(6):226-8.

7. Akyolcu N, Uğraş GA. Breast self-examınatıon: How important is it in early diagnosis?. The Journal of Breast Health. 2011; 7(1):10-4.

8. Sönmez Y, Nayir T, Köse S, et al. Behavior of women with breast cancer in the early diagnosis S. D. U. Medicine Journal. 2012; 19(4):124-30.

9. Kwok C, Endrawes G, Lee CF. Breast cancer screening beliefs questionnaire: Psychometric properties assesment of the Arabic version. European Journal of Oncology Nursing. 2016;20(1):42-8.

10. Ersin F, Bahar Z. Inhibiting and facilitating factors concerning breast cancer early diagnosis behavior in Turkish women: A qualitative study according to the health belief and health development models. Asian Pacific J Cancer Prev. 2011;12(7):1849-54.

11. Kıssal A, Beşer A. Knowledge, facilitators and perceived barriers for early detection of breast cancer among elderly Turkish women. Asian Pacific $J$ Cancer Prev. 2011;12(4):975-84.

12. Sadler GR, Dhanjal SK, Shah NB, et al. Asian Indian Women: Knowledge, attidues and behaviors toward breast cancer early detection. Public Health Nursing. 2001;18(5):357-63.

13. Tümer A, Baybek H. The rısk level of breast cancer at the workıng women. The Journal of Breast Health. 2010;6(1):17-21.

14. Carr RE. Oncology nursing essentials: Then an now. Clinical Journal of Oncology Nursing. 2015;19(2):223-25.

15. Yılmaz M, Seki Z, Gürler H, et al. Evaluation of risk factors of breast cancer in women employees in a üniversity. Dokuz Eylul University Electronic Journal of School of Nursing. 2010;3(2):65-71.
16. Benito L, Binefa G, Lluch T, et al. Defining the role of the nursein population-based cancer screening programs: A literature review. Clinical Journal of Oncology Nursing. 2014;18(4):77-83.

17. Graham H. The nurse's role in promoting breast awarness to women. Nursing Time Net. 2005;101(41):23-4.

18. Lynge E, Törnberg S, Von KL, et al. Determinants of succesful implemention of population based cancer screening programs. European Journal of Cancer. 2012;48(5):743-8.

19. Dinçel O, Başak F, Pektaș B, et al. Breast cancer risk assessment and level of knowledge in women with low levels of education. $J$ Kartal TR. 2014;25(3):181-6.

20. Donnelly TT, Al Khater A, Al Bader SB, et al. Beliefs and attitudes about breast cancer and screening practice among Arab women living in Qatar: a cross-sectional study. BMC Women's Health. 2013;13:2-16.

21. Talbert PY. An analysis of the relationship of fear and fatalism with breast cancer screening among a selected target population of African American middle class women. Journal of Social, Behavioral and Health Sciences. 2008;2(1):96-110.

22. Koç Z, Sağlam Z. Determınatıon of the knowledge and the practıce of female patients about breast cancer, preventive measures and breast self examination and effectiveness of education. The Journal of Breast Health. 2009;5(4):25-33.

23. Oluwatosin A. The rol of community health nursing in early detection of breast cancer. West African Journal of Nursing. 2008; 19(2):125-9.

24. Vogel WH. The advanced practice nursing role in a high-risk breast cancer clinic. Oncol Nurs Forum. 2003;30(1):115-22.

25. Andersen MR, Smith R, Meischke H, et al. Breast cancer worry and mammography use by women with and without a family history in a population- based sample. Cancer Epidemiol Biomarkers Prev. 2003;12(4):314-20.

26. Miller SJ, O’Hea EL, Lerner JB, et al. The relationship between breast cancer anexity and mammography: experiental avoidance as a moderator. Behavioral Medicine. 2011;37(4):113-8.

27. Aro AR, Koning HJD, Absetz P, et al. Two distinct of non-attenders in an organized mammography screening program. Breast Cancer Research Treatment. 2001;70(2):145-53.

28. Kidd AD, Colbert AM, Jatoi I. Mammography: Review of the controversy, health disparities, and impact on young african american women. Clinical Journal of Oncology Nursing. 2015;19(3):52-8.

29. Koçak S, Çelik L, Özbaş S, et al. Risk factors in breast cancer, rısk assessment and prevention: 2010 İstanbul consensus meeetıng report. The Journal of Breast Health. 2011;7(1):47-67.

30. Karakayalı FY, Ekici Y, Sevmiş Ş, et al. Gail model for determination of the risk factors of breast cancer. Turkish Journal of Surgery. 2007;23(1):12935 . 